\title{
ПОНЯТИЕ ЦИФРОВЫХ КОМПЕТЕНЦИЙ И ИХ РОАЬ В СОВРЕМЕННОМ ОБЩЕСТВЕ
}

\author{
(C) Темирова А.Б.
}

\author{
ФГБОУ ВО «Грозненский государственный нефтяной \\ технический университет имени академика \\ М.Д. Миллионщиккова» г. Грозный
}

\begin{abstract}
В данной раскрывается проблема формирования цифровых компетенций и значения этого понятия в контексте современных социальных процессов.

Современные тенденции цифровизации экономики обусловили такой феномен, как фактическую изоляцию человека, не усвоившего в достаточной мере применения цифровых технологий. Сами же по себе цифровые компетенции уже не ограничиваются навыками применения компьютерных технологий, а становятся необходимым инструментом для взаимодействия с общественными институтами вообще. Кроме этого, автор уделяет внимание и методологическим аспектам формирования самого понятия цифровых компетенций. Так, сейчас в научной среде еще идут дискуссии относительно корректности применения данной терминологии.

Существуют более узкие трактовки содержания этой категории, так и глобальное понимание значение цифровых компетенций. Практическое значение проблемы можно рассматривать в нескольких аспектах. Наиболее важный аспект-потребность реформирования системы образования в соответствии с современными требованиями, пересмотр учебных программ в соответствии с потребностями рынка труда и требований работодателей. Более широкий аспект проблемы заключается в том, чтобы способствовать интеграции в общество каждого лица, и предотвратить ситуацию, при которой возникает социальная изолячия человека через всеобъемлющую чирровизацию.

Ключевые слова: цирровые компетенции, цифровизация экономики, информационно-коммуникационные технологии, цирровое обучение, общественная коммуникация.
\end{abstract}

В условиях развития экономики, быстрой смены технологий, качественно нового социума современное образование базиру- 
ется на высокотехнологичных средствах обучения, характеризуется значительной мобильностью, универсальностью и фундаментальностью. В связи с трансформацией образования традиционная роль научно-педагогического работника меняется.

Современный научно-педагогический работник должен внедрять современные тренды в образовании, уметь выбирать и использовать современные педагогические и информационно-коммуникационные технологии для обучения учащихся и студентов; организовывать сотрудничество и коммуникацию между участниками учебного процесса; проектировать электронные ресурсы и образовательную электронную среду, быть фасилитатором и помощником для учащихся и студентов, хорошо понимать и учитывать в учебном процессе их потребности и особенности, познавательные стили обучения, новые сервисы и инструменты для эффективного сотрудничества, коммуникации, владеть навыками 21 века.

Само понятие «цифровизации» в научной среде появилось относительно недавно. В начале 1990-х годов начали употреблять данный термин: стало понятно, что на фоне масштабного проникновения компьютерных технологий в ежедневную жизнь гражданина такое явление нельзя просто свести к одному из проявлений научно-технического прогресса. Авторами, заложившими основы научного исследования цифровизации как явления, считают D. Tapscott и P. Samuelson.

Темпы распространения цифровых технологий настолько существенные, что проявления этого процесса имеют очевидное проявление даже в повседневной жизни. Впрочем, активное применение этих технологий во всех сферах экономической деятельности, цифровизация экономики происходят в течение последних нескольких десятилетий. Нынешний этап можно идентифицировать как таковой, в течение которого процессы цифровизации приобрели особенно интенсивный характер. Существует большое количество аспектов цифровизация, один из которых-необходимость приобретения всеми членами общества цифровых компетенций. Для каждого лица приобретение надлежащих цифровых компетенций имеет решающее практическое значение: сейчас целые сферы экономической деятельности отказываются от непосредственного взаимодействия с 
клиентами, и применяют информационно-коммуникационные технологии для дистанционного общения и организации самообслуживания. Следовательно, понятие «цифровых компетенций» постоянно расширяется, и оно уже не может ограничиться только образовательной сферой.

Цифровизация образования является составной частью цифрового общества в целом, где происходит наполнение реального «мира электронно-цифровыми устройствами, средствами, системами и установлением электронного обмена информацией между ними».

В процессе цифровизации, заключающемся в «достижении цифровой трансформации существующих и создание новых отраслей экономики, а также в преобразовании сфер жизни в новые, более эффективные и современные», важна роль системы образования. [3]

Задача статьи состоит в том, чтобы раскрыть современное содержание понятия «цифровые компетенции», и показать их значение для функционирования общества в условиях массового распространения информационно-коммуникационных технологий.

Внедрение цифровых технологий является важным для всех сфер и отраслей образования, в частности для подготовки педагогов, образовательной инфраструктуры, методологии (педагогики) и учебно-методических ресурсов, а также управления на всех уровнях системы образования.

Быстрое развитие современного общества, цифровых технологий и инновационных средств обучения требуют от будущих специалистов новых профессиональных знаний и умений, пересмотра подходов по формированию их профессиональной компетентности. Активное использование цифровых технологий в образовании способствует эффективности образовательного процесса на всех его уровнях и формированию профессиональных компетентностей будущих специалистов. Формирование компетентностей неразрывно связано с информатизацией образования. Информатизация образования является одним из основных направлений реформирование учебных заведений, обусловленным потребностями современного общества, в которому главным является индивидуальное развитие личности. 
На основе анализа научной литературы нами определено, что «компетентность - это обладание определенной компетенцией, а компетенция - это наличие у субъекта совокупности взаимосвязанных личностных качеств, а именно знаний, умений и навыков.

Важной составляющей профессиональной компетентности будущих педагогов определено цифровую компетентность, которая предполагает способность и умение логического и системного использования информационных технологий.

Цифровая компетентность позволяет человеку быть успешной в современном информационном пространстве, управлять информацией, оперативно принимать решения, формировать важные жизненные компетенции. В сегодняшних условиях наблюдается быстрый темп развития информационных технологий, постоянно растет количество пользователей Интернета, постоянно появляются различные устройства, призванные упрощать жизнь современного человека. Такие изменения влияют на все сферы жизни, включая и образование. Растут и требования к личности современного учителя. Будущий педагог должен свободно владеть современными технологиями и

Существует несколько подходов к пониманию содержания понятия «цифровые компетенции»; в соответствии с одним из общепризнанных толкований, цифровые компетенции (применительно к определенному лицу) - это знания и навыки, которые необходимы для корректного, эффективного и безопасного использования цифровых технологий, а также существования в обществе, которое насыщено цифровыми технологиями.

Приобретение цифровых компетенций нельзя свести к одной из составляющих образовательного процесса, отождествить этот процесс с получением профессии. В отличие от предыдущих этапов научно-технической революции, цифровизация экономики отличается принципиально большими масштабами: проникновение цифровых технологий является всеобъемлющим, и происходит в очень сжатые сроки.

Можно выделить несколько «уровней» проблематики приобретения цифровых компетенций:

1) приобретение цифровых компетенций лицом как составляющая повышения собственной специальности, конкурентоспособности на рынке труда; 
2) приобретение цифровых компетенций как части процесса социализации личности, ее интеграции в современной мир.

В первом случае потребность в приобретении цифровых компетенций является более очевидной: постоянное появление нового оборудования, новых производственных процессов требует от работников обучения и самосовершенствования.

Цифровые технологии в течение последних десяти-пятнадцати лет коренным образом изменили основы труда во многих профессиях. Человек, который не совершенствует собственные профессиональные навыки и не осваивает новые технологии, рискует быстро потерять собственную конкурентоспособность на рыке труда.

Во втором случае речь идет о потребности человека обладать цифровыми компетенциями ввиду того, что сейчас цифровизация влияет почти на все сферы жизни. То есть лицо, не обладающее необходимыми компетенциями, рискует потерять доступ к большому количеству общественных благ, может лишить себя возможности принимать полноценное участие в общественной жизни, пользоваться спросом на рынке труда. Различие между лицом, обладающей необходимыми цифровыми компетенциями, и лицом, лишенным такой возможности, столь велика, что речь уже идет о цифровом неравенстве.

Как уже отмечалось, процесс приобретения цифровых компетенций нельзя свести к обучению. Это обусловлено как тем, что сам характер цифровых технологий коренным образом отличается от технологий предыдущих этапов научно-технической революции, так и тем, что овладеть цифровыми компетенциями единовременно невозможно.

Проблема, среди прочего, заключается и в том, что цифровые компетенции лица требуют постоянного обновления, и в том, что овладеть такими компетенциями должны все члены общества (в той или иной степени).

То есть, приобретение цифровых компетенций нельзя свести только к повышению квалификации работников: эта проблема имеет общественный масштаб. [1]

Данная проблема уже давно замечена научным сообществом. Впрочем, поначалу она сводилась к потребности компьютеризации системы образования и повышения компьютер- 
ной грамотности населения. Впрочем, довольно быстро стало понятно, что в данном случае речь идет о явлении иной природы. Сейчас обретение цифровых компетенций рассматривается именно как потребность всего общества.

Данная проблема была идентифицирована и на уровне государственного управления. В качестве ответа были разработаны и внедрены механизмы формирования цифровых компетенций в обществе. Опыт реализации таких механизмов в разных странах очень отличный: успех их внедрения зависит от Обобщая существующую практику, можно выделить следующие виды механизмов (табл. 1).

Естественно, что наиболее распространенным механизмом формирования цифровых компетенций в обществе являются государственные программы, направленные на адаптацию общества к условиям цифровой экономики. Сейчас национальная политика по цифровизации в разных странах существенно отличается. Так же, как и степень готовности общества к существованию в условиях цифровой экономики. Вместо таких государственных программ также зависит и от приоритетов национальных правительств, и от вызовов, с которыми сталкивается государство. Так, среди существующих программ можно выделить такие, приоритетами для которых является преодоление цифрового неравенства, интенсификация инновационной активности населения, повышение конкурентоспособности, и др. Поскольку проблема приобретения цифровых компетенций имеет общенациональный масштаб, именно государство должно быть главным инициатором его преодоления. [4]

Сфера среднего образования наиболее пригодна для того, чтобы подготовить к существованию в условиях цифровой экономики новое поколение. С одной стороны, в настоящее время цифровые технологии очень доступны, и их применение не требует больших вложений. Каждый человек, который задействован в экономической жизни, имеет возможность приобретать такие компетенций через повышение квалификации, саморазвитие. С другой стороны, именно базовые образовательные навыки, полученные в средней школе, формируют будущее мировосприятие человека. 
Таблица 1. Механизмы формирования циифровых компетенций в обществе

\begin{tabular}{|c|c|}
\hline Механизм & Суть механизма \\
\hline $\begin{array}{l}\text { Государственные } \\
\text { программы распро- } \\
\text { странения цифровых } \\
\text { компетенций }\end{array}$ & $\begin{array}{l}\text { Создание образовательных институтов, зада- } \\
\text { чей которых является реализация образова- } \\
\text { тельных } \\
\text { программ по приобретению цифровых компе- } \\
\text { тенций, содействие } \\
\text { самосовершенствованию граждан }\end{array}$ \\
\hline $\begin{array}{l}\text { Перестройка систе- } \\
\text { мы среднего } \\
\text { образования }\end{array}$ & $\begin{array}{l}\text { Внедрение нового стандарта среднего образо- } \\
\text { вания, который предусматривает } \\
\text { усвоение цифровых компетенций с самого на- } \\
\text { чала обучения, } \\
\text { использование цифровых технологий как ос- } \\
\text { новы учебного процесса }\end{array}$ \\
\hline $\begin{array}{l}\text { Реорганизация си- } \\
\text { стемы } \\
\text { университетского } \\
\text { образования }\end{array}$ & $\begin{array}{l}\text { Использование возможностей системы высше- } \\
\text { го образования с целью формирования } \\
\text { нового подхода к получению профессии, под- } \\
\text { готовка нового поколения } \\
\text { работников к необходимости постоянно само- } \\
\text { совершенствоваться }\end{array}$ \\
\hline $\begin{array}{l}\text { Интенсификация } \\
\text { корпоративного } \\
\text { образования }\end{array}$ & $\begin{array}{l}\text { Постоянное обучение и повышение квалифи- } \\
\text { кации работников в частном } \\
\text { секторе является одним из весомых факторов } \\
\text { усвоения цифровых компетенций в обществе } \\
\text { в целом. }\end{array}$ \\
\hline $\begin{array}{l}\text { Создание учебных } \\
\text { платформ }\end{array}$ & $\begin{array}{l}\text { Использование Интернет-платформ для массо- } \\
\text { вого усвоения цифровых } \\
\text { компетенций, их обновление, распространение } \\
\text { информации о появлении новых } \\
\text { технологий, актуальные учебные курсы }\end{array}$ \\
\hline $\begin{array}{l}\text { Побуждение к овла- } \\
\text { дению } \\
\text { цифровыми компе- } \\
\text { тенциями на } \\
\text { микроуровне }\end{array}$ & $\begin{array}{l}\text { Овладение цифровыми компетенциями может } \\
\text { происходить и на уровне } \\
\text { отдельных компаний, организаций: если в } \\
\text { частном секторе экономики } \\
\text { существует тренд на распространение цифро- } \\
\text { вых технологий и их усвоение } \\
\text { населением, то это может иметь и общий об- } \\
\text { щественный эффект }\end{array}$ \\
\hline
\end{tabular}


Следовательно, именно в средней школе у человека закладывается уровень восприятия технологий, базовые навыки. Привлечение сферы среднего образования к процессу формирования цифровых компетенций способно гарантировать высокий уровень их усвоения. Следует констатировать, что сейчас сфера среднего образования в России не может выполнять в полной мере такую функцию, в первую очередь из-за неудовлетворительного материально-технического обеспечения учебного процесса, а также из-за того, что данной сфере на протяжении длительного времени не проводились системные реформы, и сейчас ее эффективность крайне мала. То есть, в российских условиях применить такой механизм в полной мере пока не удастся.

Привлечение сферы высшего образования является значимым механизмом, ведь именно это образовательное звено является таким, которое придает человеку специальность и формирует ее мировосприятие. Следует отметить, что степень цифровизации общественных и экономических процессов (в том числе получение профессии) таков, что человек должен обладать цифровыми компетенциями уже для того, чтобы получить образование. То есть, большее значение в контексте формирования базовых компетенций принадлежит все же сфере среднего образования. Вместо этого, роль учреждений высшего образования в формировании цифровых компетенций должно заключаться в том, чтобы получаемая профессия уже включала необходимые навыки. Целесообразно, чтобы именно в процессе получения высшего образования у человека формировалось корректное понимание сущности цифровизации, ее роли в дальнейшей жизни.

Скорость появления новых цифровых технологий такова, что цифровые компетенции нельзя усвоить единовременно. То есть, уже во время получения первого высшего образования человека следует сориентировать, что полученные знания будут актуальными в течение весьма короткого промежутка времени.

Такой механизм, как применение интернет-платформ для формирования цифровых компетенций в общество не ново. Онлайн обучение практикуется уже довольно давно, однако, действенность такого механизма сейчас небольшая. Платформы, ориентированные на массовое бесплатное обучение, при том, что обладают рядом преимуществ, имеют и несколько существенных недостатков. К преимуществам платформ можно от- 
нести то, что пользователям предлагается заранее подобранный учебный материал, и нет необходимости тратить время на самостоятельный поиск необходимой информации. Недостатком является то, что пользователи, которые предпочитают повышать свои навыки самостоятельно, сталкиваются с проблемой «засорения» информационного пространства, недостаточной самоорганизации. Однако, именно образовательные онлайн платформы сейчас считаются наиболее перспективными с точки зрения усвоения цифровых компетенций. При том, что они уступают классическим университетам, когда речь идет о получении фундаментального образования, именно платформы можно больше пригодны для применения в качестве информационной базы для усвоения новых компетенций. Таким образом можно утверждать, что Интернет-платформы, несмотря на недостаточную эффективность на данный момент, является оптимальным каналом для распространения среди населения актуальной информации.

Побуждение к овладению цифровыми навыками на микроуровне является общей тенденцией, его проявление можно наблюдать в повседневной жизни. Так, стремление компаний, занимающихся банкингом, розничной торговлей минимизировать применение человеческого труда заставляет покупателей усваивать новые технологии. Перспектива предоставление банковских услуг только онлайн означает, что вскоре каждый человек, который не имеет достаточных цифровых компетенций, будет неспособна осуществлять любые финансовые операции. Такое явление, как электронная торговля, также требует от потребителей освоения цифровых технологий. Так, по состоянию на 2017 г. можно говорить о паритете между электронной торговлей и традиционной торговлей. Зато тенденция распространения новых цифровых технологий такова, что вскоре речь будет идти о том, что большую долю товаров и услуг можно купить будет только в Интернете. Важно и то, что для многих направлений предпринимательской деятельности масштабная автоматизация не имеет альтернативы. Таким образом, для многих компаний постоянное обучение собственных клиентов привычной практикой. Данный механизм опирается на принцип «учись, используя».

Перечисленные механизмы формирования цифровых компетенций в обществе в каждой стране применяются с разной степенью интенсивности. К тому же, фактом является то, что 
фактическая готовность каждой страны до новых реалий (масштабной цифровизации) очень сильно отличается. [5]

Применение указанных механизмов в России и заграницей имеет свою специфику. Для ситуации в России присущи следующие черты:

1) запоздалая реакция властных органов на вызовы, связанные с цифровизацией;

2) декларативный характер государственной политики в отношении цифровых технологий;

3) неоднородность российского общества.

Степень усвоения цифровых компетенций в российском обществе неодинаков, в зависимости от социальной группы. Отличие в степени усвоения цифровых компетенций между возрастными группами естественна: поколение, которое учится в учреждениях среднего образования сейчас, уже усвоила цифровые компетенции в достаточной мере.

Для российских реалий присуще еще одно отличие: часть общества, которую условно можно назвать «средним классом», также обладают цифровыми компетенциями в достаточной степени. То есть люди, которые интегрированы в рынок труда, самостоятельно осуществляют финансовые операции, путешествуют, и тому подобное, уже усвоили цифровые компетенции. В то же время, остальное общество демонстрирует крайне низкий уровень. [2]

Сегодня в мировом образовательном пространстве нет единого термина для четкого определения цифровой компетентности будущих учителей. Большинство ученых придерживаются одного мнения в том, что для педагога является недостаточным владение только базовыми навыками в области информационных технологий. По нашему мнению, цифровая компетентность является важным компонентом профессиональной компетентности современного педагога. Цифровая компетентность сочетает знания и умение использовать цифровые технологии для организации образовательного процесса, критически оценивать информационные ресурсы в целесообразности их применения в будущей профессиональной деятельности, применять технологические инновации.

Важной предпосылкой формирования цифровой компетентности является готовность будущих специалистов к овладению и применению цифровых технологий. 
Несмотря на большое количество исследований, посвященных данной проблеме, вопрос трактовки понятия цифровой компетентности будущих учителей, определение ее структуры и содержания требуют дальнейшего изучения.

В дальнейшем исследовании важным является исследование подходов по созданию модели формирования цифровой компетентности будущих учителей, определения условий

формирование цифровой компетентности учителей, перспективы внедрения разработанной модели для обеспечения непрерывного профессионального развития учителя.

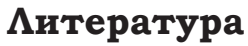

1. Бабкин А.В., Буркальцева Д.Д., Костень Д.Г., Воробьев Ю.Н. Формирование цифровой экономики в России: сущность, особенности, техническая нормализация, проблемы развития // Научно-технические ведомости Санкт-Петербургского государственного политехнического университета. Экономические науки. 2017. Т. 10. № 3. С. 9-25.

2. Городенко Л. Н. цифровое и информационное неравенство в сетевой коммуникации // Информационное общество. 2012. №16. С. 56-59.

3. Ибрагимова Л.А., Петрова Г.А. Профессиональная компетенция учителя: содержание, структура // Вестник Нижневартовского государственного гуманитарного университета. 2010. №1. С. 52-56.

4. Кауфман Н. Ю. Трансформация управления знаниями в условиях развития цифровой экономики // Креативная экономика. 2018. Том 12. № 3. С. 261-270.

5. Современная цифровая образовательная среда// Портал СЦОС в Российской Федерации.[электронный ресурс]// http:// neorusedu.ru/ 